\title{
The impact of tropospheric ozone pollution on trial plot winter wheat yields in Great Britain - An econometric approach
}

\author{
Evridiki Kaliakatsou $^{\mathrm{a}, *}$, J. Nigel B. Bell ${ }^{\mathrm{a}}$, Colin Thirtle ${ }^{\mathrm{a}, \mathrm{b}}$, Daniel Rose ${ }^{\mathrm{c}}$, Sally A. Power ${ }^{\mathrm{c}}$ \\ ${ }^{a}$ Centre for Environmental Policy, Imperial College London, South Kensington Campus, London SW7 2AZ, United Kingdom \\ ${ }^{\mathrm{b}}$ Department of Agricultural Economics Extension and Rural Development, University of Pretoria, Pretoria, 0002, South Africa \\ ${ }^{\mathrm{c}}$ Division of Biology, Imperial College London, Silwood Park Campus, Ascot SL5 7PY, United Kingdom \\ Econometric study of British winter wheat trial plot data suggests lower economic loss than predicted from experiments.
}

\section{A R T I C L E I N F}

\section{Article history:}

Received 18 January 2009

Received in revised form

20 October 2009

Accepted 22 October 2009

\section{Keywords:}

Tropospheric ozone

Winter wheat

Trial plot data

Econometrics

Yield loss

\begin{abstract}
A B S T R A C T
Numerous experiments have demonstrated reductions in the yields of cereal crops due to tropospheric $\mathrm{O}_{3}$, with losses of up to $25 \%$. However, the only British econometric study on $\mathrm{O}_{3}$ impacts on winter wheat yields, found that a $10 \%$ increase in AOT40 would decrease yields by only $0.23 \%$. An attempt is made here to reconcile these observations by developing AOT40 maps for Great Britain and matching levels with a large number of standardised trial plot wheat yields from many sites over a 13-year period. Panel estimates (repeated measures on the same plots with time) show a $0.54 \%$ decrease in yields and it is hypothesised that plant breeders may have inadvertently selected for $\mathrm{O}_{3}$ tolerance in wheat. Some support for this is provided by fumigations of cultivars of differing introduction dates. A case is made for the use of econometric as well as experimental studies in prediction of air pollution induced crop loss.
\end{abstract} (C) 2009 Elsevier Ltd. All rights reserved.

\section{Introduction}

Scientific experiments in many countries have shown that cereal crop yields can be reduced substantially at levels of ozone below those which damage human health occurs (PORG, 1997). The majority of these studies have employed open - top chambers, in which plants are ventilated with clean charcoal-filtered air or else with ambient air, with or without different concentrations of $\mathrm{O}_{3}$ added to generate dose-response relationships. Under the auspices of the United Nations Economic Commission for Europe's (UNECE) Convention on Long Range Transboundary Air Pollution, a critical level of $\mathrm{O}_{3}$ has been established for sensitive agricultural crop species. Currently this is $3000 \mathrm{ppb}$ h, equivalent to the sum of concentrations exceeding a threshold of $40 \mathrm{ppb}$ over daylight hours during a 3 month growing season (LRTAP Convention Mapping Manual, 2004), known as the AOT40. This value is based on opentop chamber experiments with spring wheat in central and northern Europe (Fuhrer et al., 1997) and this corresponds to the smallest significant yield loss (4-5\%) detected with 99\% certainty for a critical level of approximately $3000 \mathrm{ppb}$ h (PORG, 1997).

\footnotetext{
* Corresponding author.

E-mail address: eviekal@googlemail.com (E. Kaliakatsou).
}

However, there are many uncertainties in this experimentally based approach, such as modification of microclimate by the chambers and the massive variation in climatic and edaphic conditions across Europe, which can have a major impact on crop sensitivity at any given location. Recently a flux based critical level to take into account regional influences on crop sensitivity to ozone has been established (LRTAP Convention Mapping Manual, 2004).

Relatively few attempts have been made to estimate economic losses across Europe arising from $\mathrm{O}_{3}$-induced yield reduction. The most recent of these is by Holland et al. (2006), who used the AOT40 approach to make a best estimate of $€ 6.7 \times 10^{9}$ for 23 crops in 47 countries. However, the authors noted a number of major areas of uncertainty attached to this estimate, the most important of which, in ascending order, are: dose-response functions, changes in $\mathrm{O}_{3}$ concentrations with crop height and crop yield estimation in the field.

Feng et al. (2008) quantified the impact of elevated $\mathrm{O}_{3}$ on wheat using a meta-analysis of data published between 1980 and 2007 although they included concentrations up to $200 \mathrm{ppb}$. Their analysis indicated that elevated $\mathrm{O}_{3}$ concentrations decreased grain yield by up to $29 \%$ and above ground biomass by $18 \%$. Amongst growing stages, the impact of ozone was most significant during the grain filling (Feng et al., 2008).

An alternative approach is to examine yields in the field in relation to prevailing $\mathrm{O}_{3}$ and climate regimes. This offers an attractive route to assessing $\mathrm{O}_{3}$ losses using real farm data and 
avoiding the need to extrapolate dose-response relationships derived from experimental studies, which have their own disadvantages.

There has been only one farm level study on the impact of $\mathrm{O}_{3}$ in Great Britain (Shankar and Neeliah, 2005). This used balanced panel data (repeated measures on the same individuals with time) from 116 farms growing winter wheat annually, from 1993 to 1998 using ozone as an input in the estimation of a production function. The elasticity of yield with respect to ozone was only -0.023 (i.e. $0.23 \%$ reduction in yield per $10 \%$ increase in AOT40) implying an extremely small loss in yield due to $\mathrm{O}_{3}$. In contrast, a similar study by Young (1993) for wheat in Alberta found an elasticity of -2 , which is two orders of magnitude larger.

This paper attempts some reconciliation between the above mentioned anomalies, by applying the econometric approach to trial plot yields. The advantage of this approach is that a high degree of standardisation has been employed in the management of trial plots, thereby reducing the complexity inherent in farm scale data. The expectation is that the yield loss on the trial plots will be greater than on farms, as these sites grow all cultivars, whereas it is likely that farmers inadvertently select for $\mathrm{O}_{3}$ tolerance in locations with the highest levels of the pollutant. This hypothesis is tested by an experimental fumigation of 6 major wheat cultivars, which have been grown extensively in the Great Britain during different periods between 1923 and the present day, in order to determine if more recently introduced cultivars are indeed more $\mathrm{O}_{3}$ tolerant.

\section{Materials and methods}

\section{1. $\mathrm{O}_{3}$ data}

Monitored $\mathrm{O}_{3}$ data were obtained from the UK National Air Quality Information Archive (www.airquality.co.uk). Only rural monitoring stations were used in the analysis, as urban locations normally have lower $\mathrm{O}_{3}$ concentrations than farming areas, such that the former are more representative of exposure of wheat in more rural locations (Sillman, 1999). These monitoring stations give continuous hourly concentrations of $\mathrm{O}_{3}$, but do not provide comprehensive coverage, with only 13 rural sites included in the network in 1992. Therefore it was necessary to use GIS techniques to extrapolate $\mathrm{O}_{3}$ for the entire surface of Great Britain.

The AOT40 was calculated for each monitoring station for each year from 1992 to 2004, inclusive, from 1st May to 31st July (LRTAP Convention Mapping Manual, 2004). Over these months, winter wheat is most susceptible to $\mathrm{O}_{3}$ as it coincides with the grain filling period and the weather conditions (high temperatures and insolation) are such that they lead to higher concentrations (Ollerenshaw and Lyons, 1999).

The aim was to produce AOT40 maps for the daylight period, defined between 08:00 and 20:00 during the summer months. However, during the daylight period, ozone pollution concentrations are subject to large fluctuations and therefore direct interpolation for the daylight hours might lead to overestimation or underestimation of the predicted values. Therefore the interpolation was performed for the afternoon hours (12:00-16:00) when $\mathrm{O}_{3}$ values observed in a specific rural location are representative of a wider geographical area (Loibl et al., 1994; Coyle et al., 2002). Values were then adjusted for altitude to produce representative maps for the daylight hours (08:00-20:00), following the approach used by Coyle et al. (2002). The positive correlation between $\mathrm{O}_{3}$ concentrations and altitude has been well demonstrated in several studies (Loibl et al., 1994; Coyle et al., 2002; Hunova et al., 2003).

The most common interpolation methods are Inverse Distance Weighting (IDW) and Kriging. The former is a simple interpolation approach which assumes that the influence of neighbouring points on interpolated values is a declining function of distance between stations and can be estimated by averaging the values near the measured data points. Kriging is also a distance weighting method, but its weights depend also on the overall spatial arrangement of the measured points and their values.

Both interpolation techniques were performed, however the maps which were produced with the IDW technique did have some drawbacks. The surfaces were rough and with "bulls eyes" effect around sample points. This happened because the IDW method assumes that the interpolated values are exclusively a function of the distance between sample points and that all the interpolated values vary between maximum and minimum values of the sample points (Bonham-Carter, 1994). IDW is considered more appropriate to use in cases of dense sample networks of uniformly spaced, spatially autocorrelated observations where the main interest would be the spatial variation near the sample rather than the smoothness of the map (Diem and Comrie, 2002). Taking all of the above into account, Kriging was considered to be a more appropriate method since it produced smoother surfaces which coincided with the general ozone trends in Great Britain.

\subsection{Trial plot data}

British trial plot data span 13 years (1992-2004), for 66 cultivars of winter wheat grown in 149 trial plot sites. Fig. 1 shows the distribution of trial plot sites and of ozone recording stations. Trial plots provide the data on which the UK Home Grown Cereals Authority (HGCA) bases its lists of recommended cultivars for farmers (www.hgca.com/varieties/rl\%2Dplus/); these have three dimensions: location, cultivar and time. Since the data have more than one dimension, panel data models are required.

Panel or longitudinal data are common in economics, where the data contain observations on the same individuals over several periods. Such datasets can be balanced, when the same individuals are observed over the entire sample period, or unbalanced when not all the same individuals are observed over the time period. In the current case, cultivars and site locations can change over time, as new cultivars substitute the older ones and new trial plot sites are introduced. For the present analysis, since not all individuals are universally present, the data represent an unbalanced panel of 9385 observations.

Wheat was selected because it is considered one of the more $\mathrm{O}_{3}$ - susceptible crops; winter wheat was the specific focus of our study because it allows direct comparisons with the Shankar and Neeliah (2005) results, because it is the most important cereal crop in British agriculture and because trial plots for this cultivar are widely distributed, as Fig. 1 shows. The trial plot data provide an opportunity to make accurate measurements of the impacts of $\mathrm{O}_{3}$, as there are a very large number of observations and the experimental crops are grown under relatively controlled agronomic conditions. The specifications for the trial plots vary according to cultivar. The general specifications applicable to all cultivars include a minimum drilled width of $1.1 \mathrm{~m}$ and an inter-plot gap of a maximum $0.55 \mathrm{~m}$ to give a total width of not 
less than $1.65 \mathrm{~m}$ and the land should ideally be irrigated. Fertilisers and pesticides are applied as appropriate for commercial crops to give a hypothetical maximum yield; data are excluded where $>5 \%$ damage occurs due to extreme weather conditions and other adverse factors (e.g. insect pests) (HGCA Recommended List, Cereal Trials Protocol, 2007-2008).

\subsection{Models and estimation}

Matching AOT40 levels with trial plot yields for each site and year provides the basic information for econometric estimation. However, there was a great deal of choice as to which other variables should be included and the method of estimation. The basic choice was between, a massive exercise on collecting data for all the variables (not all known) that affect trial plot yields, or using two-way error components, with fixed or random effects, to remove all such impacts. The models used remove the effects of any factors that are time invariant, such as the different soil types at different sites. This is problematic only if such effects are of interest and in this case they are not.

In particular, the effects of weather on yields are well demonstrated by Landau et al. (2000), who used over a dozen variables to capture climatic effects. This level of detail cannot be replicated across either space or time. The problem is that only simple variables like annual rainfall are available on this scale, and then not well matched to the sites. Other weather variables, such as hours of sunlight, cause problems in view of their role in $\mathrm{O}_{3}$ generation. Thus, including sunlight would make $\mathrm{O}_{3}$ endogenous and introduce a new set of problems, as a multiple equation model would be needed so we opted for removing the effects of all such variables by econometric means.

The modelutilised here is an unbalanced panel, with the data assumed to be log linear, which allows coefficients to be interpreted as elasticities. This implies that the relationships are initially exponential and a transformation to natural logarithms imposes linear relationships that are easier to estimate. As pointed out, panel datasets have multiple observations on the same individuals. Each element has two subscripts, $i$, which indicates the group identifier and $j$ which is the within-group index and usually denotes time (Baum, 2006). However, the within-group identifier could be some unit other than time, such as the type of cultivar.

The panel regression then can be stated as follows:

$y_{\mathrm{ij}}=\alpha+\beta X_{\mathrm{ij}}+\varepsilon_{\mathrm{ij}} \quad i=1, \ldots, N ; j=1, \ldots J$

where $y$ is the yield vector, $i$ denotes the site and $j$ denotes the cultivar. $X$ is a matrix of explanatory variables and $\varepsilon_{i j}$ a composite error component. The composite error term can account for the individual heterogeneity (assumed to be time invariant) and the random disturbance or for the individual heterogeneity, the unobservable within-group specific effects and the random disturbance. The first case is referred to as the one-way error components model and the second case as the two-way error components model.

The disturbances in the two-way error components model are:

$\varepsilon_{i j}=\mu_{i}+\lambda_{j}+v_{i j}$

where $\mu_{i}$ denotes the unobservable site effects, $\lambda_{j}$ the unobservable cultivar effects and $\nu_{i j}$ the remaining stochastic disturbance. If $\mu_{i}$ and $\lambda_{j}$ are assumed to be fixed parameters to be estimated and $\nu_{i j}$ is assumed to be independent and identically distributed (IID) with mean 0 and variance $\sigma_{\nu}^{2}$, this is the two-way fixed effects error components model (Baltagi, 2005). If $\mu_{i}$ and $\lambda_{j}$ are assumed to be random, independent of each other and of $\nu_{i j}$, then it is the two-way random effects error components model. ${ }^{1}$ The fixed effects model removes all time-invariant site-specific differences, such as soil type and altitude, as required in this application.

The regressions were run as pooled ordinary least squares, then one-way error components, then two-way, with tests to show that this progression was justified. ${ }^{2}$ The one-way error components model used site as the group identifier, which amounts to using an individual specific intercept dummy for each of the $\mathrm{N}$ individuals to remove the unobserved site-specific differences that are not included in the regression. Dummy variables are used to indicate whether within a particular subgroup of the data a particular condition is satisfied (Baum, 2006). Dummy variables take the values of 1 and 0 only, with 1 indicating that the particular condition is satisfied and 0 otherwise.

The two-way error components model added cultivars as the within-group identifier. Time was excluded as this third dimension and it was added as a fixed effect simply by including twelve dummies, for all but one year (to avoid co-linearity). Thus, the matrix $X_{i j}$ is comprised of the ozone measure, annual dummies and a dummy if the previous crop was a cereal. The trial plots apply fertiliser and

\footnotetext{
1 The random effects model is not further explained, since although it was estimated as an alternative, following the standard convention, it was rejected by the appropriate test.

2 The statistical package which was used for this analysis is NLOGIT (Econometric Software Inc.) that has the ability to deal directly with unbalanced panels and twoway error components.
}

pesticides to maximise yield, so data on inputs are not needed. The trial is also abandoned in cases where weather (such as hail) or other stresses cause significant damage.

2.4. Screening fumigation experiment for $\mathrm{O}_{3}$ sensitivity of winter wheat cultivars introduced during 1923-1996

The hypothesis that inadvertent selection for $\mathrm{O}_{3}$ tolerance may have taken place during the course of plant breeding was examined by means of a fumigation experiment in 2003, on 6 winter wheat cultivars introduced from 1923 onwards, with the most recent cultivar dating from 1996. Econometric methods were precluded since the first reliable continuous ground-level UK ozone monitoring began in rural southern England in 1971 (Atkins et al., 1972).

Table 1 shows the leading wheat cultivars employed and the dates of their introduction and wide-scale use in Britain. Seeds were supplied by the National Institute of Agricultural Botany, UK. The seeds were sown in John Innes No. 2 compost in $1 \mathrm{~L}$ pots and the seedlings thinned to one plant per pot. After 2 weeks, three replicates of each cultivar were placed into one of eight Perspex growth chambers (each $0.637 \mathrm{~m}^{3}$ ) in a glasshouse; four chambers were ventilated with charcoal filtered air and the remainder received the same air with the addition of $70 \mathrm{ppb} \mathrm{O}_{3}$ (generated from cylinder oxygen) for $8 \mathrm{~h} \mathrm{~d}^{-1}$ for 24 days. The experiment was conducted in August 2003. The two and a half air changes per minute through the chambers maintained temperatures between 15 and $24{ }^{\circ} \mathrm{C}$ throughout the experimental period. At the end of this time plants had reached growth stage 8 , and injury was assessed as the numbers of leaves per plant with any degree of necrotic tissue and/or yellow leaves. The latter indicates senescence, which is generally viewed as a good indicator of agricultural yield loss (Ashmore, 2002).

Logistical constraints precluded growing the plants to maturity, so an assessment of impacts on grain yield was not carried out.

Data were arcsin transformed and then analysed using linear mixed effects models. This approach takes into account not only the pseudo-replication within the chamber but also the effects of random variables such as chamber position for which the influence on the experiment is unpredictable.

\section{Results}

The interpolated AOT40 values for Britain are shown in Fig. 2, for 1992, 1995, 1998 and 2004 in order to illustrate years with markedly different $\mathrm{O}_{3}$ concentrations and distributions. This shows that 1992 and 1995 were years with substantially greater levels of pollution than 1998 and 2004, while in all cases there was a general trend of declining concentrations from the south-east northwards. The examples shown in Fig. 2 demonstrate that, in Britain, temporal and spatial variability is large within the overall dataset, thereby facilitating correlative statistical analysis.

Fig. 3 shows the mean yield for all cultivars, sites and years. There is both a rising trend and considerable annual variation, with the highest yields in 1999 and 2000. Table 2 reports summary statistics for the full sample and for the 4 major cultivars on which there were over 200 observations. It can be seen that the mean AOT40 just exceeds the critical level for agricultural crops at the trial sites while the maximum is almost three times higher than this. Fig. 4 shows the yields of four of the most popular cultivars over time: Consort appears to give the highest yield (tonnes/ha), followed in order by Riband, Hereward and Soissons.

Table 3 shows the progressive improvement in test statistics, which justifies the choice of the two-way fixed effects error components model, with site and cultivar as the stratification variables. It should be noted that the site dummies, which dispose of the unobserved site-specific effects, can alone explain $0.47 \%$ of the variance in yields. The $X$ variables alone account for only $0.16 \%$

Table 1

Leading wheat cultivars from 1923 onwards.

\begin{tabular}{ll}
\hline Variety & Era \\
\hline Square Head Master & $1923-1953$ \\
Cappelle Desprez & $1954-1972$ \\
Maris Huntsman & $1973-1982$ \\
Avalon & $1983-1989$ \\
Riband & $1990-1995$ \\
Consort & From 1996 \\
\hline
\end{tabular}




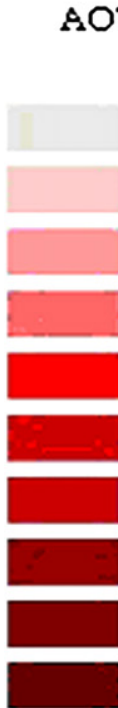

$$
0 \cdot 900
$$

$900 \cdot 1500$

$1300 \cdot 2000$

$2000 \cdot 3000$

$3000 \cdot 4000$

$4000 \cdot 5000$

$5000 \cdot 6000$

$6000 \cdot 3000$

$3000 \cdot 8000$

$8000 \cdot 12000$
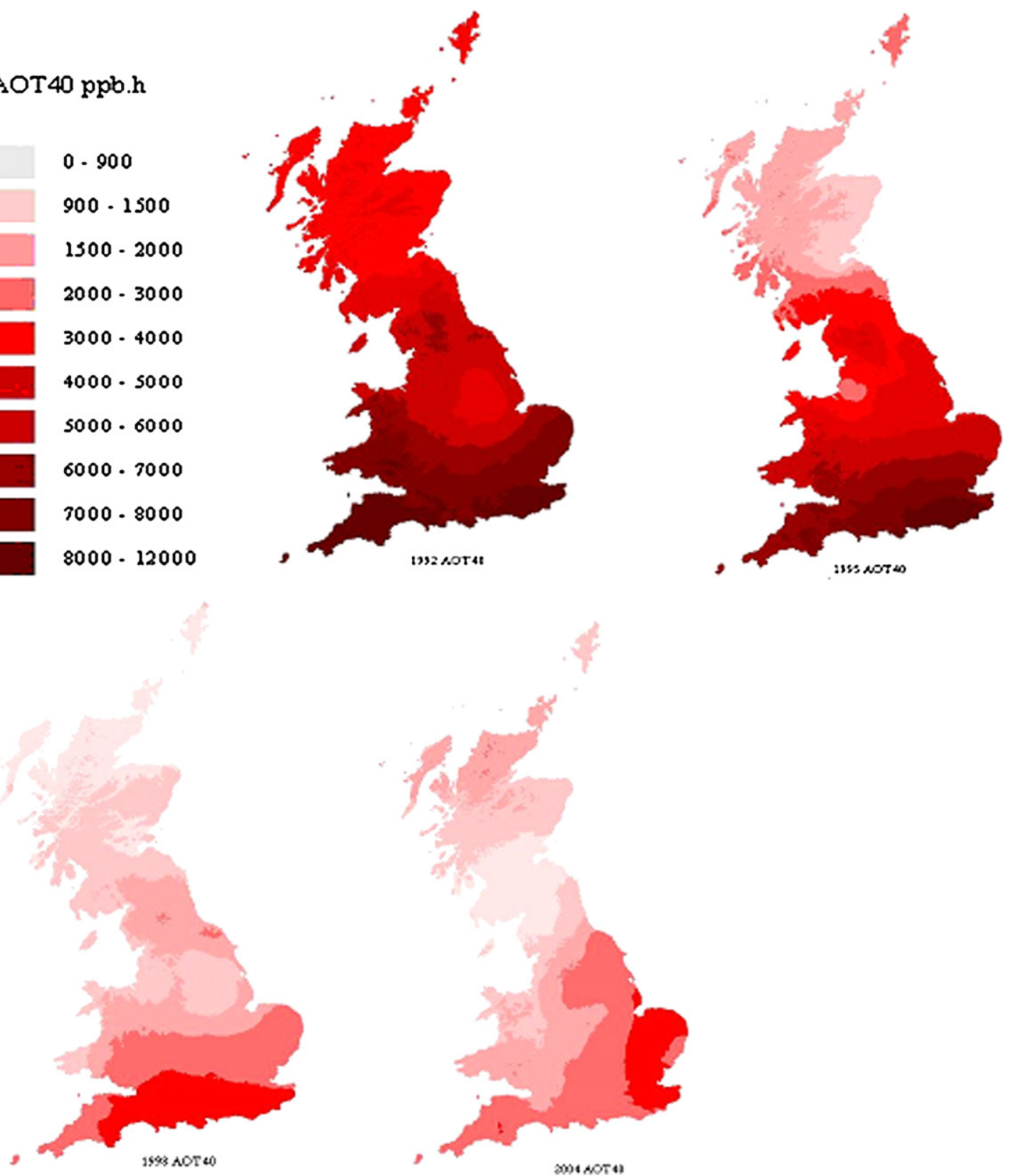

Fig. 2. Ozone maps for four years with differing ozone distributions.

of the variance and adding the second error component to the site dummies and the $X$ variables increases the explanatory power by only $0.05 \%$.

The coefficients for the preferred model are reported in Table 4, where the object of the exercise is unbiased measurement of the elasticity of yields with respect to ozone. The value of 0.054 indicates that for a $10 \%$ increase in the AOT 40 , yield reduces by $0.54 \%$. This value is modest, but it is 2.3 times the size of the farm level coefficient estimated by Shankar and Neeliah (2005). This elasticity is fairly typical of our results, which varied from 0.047 for a oneway fixed effects error components model, to a high of 0.075 for a two-way random effects model with site and year as the stratification variables. The random effects model was, however, rejected in favour of fixed effects, by the Hausman test.

The average effect of following after a cereal crop, is a yield reduction of $8.9 \%$ (that is an $8.9 \%$ shift in the intercept), reflecting

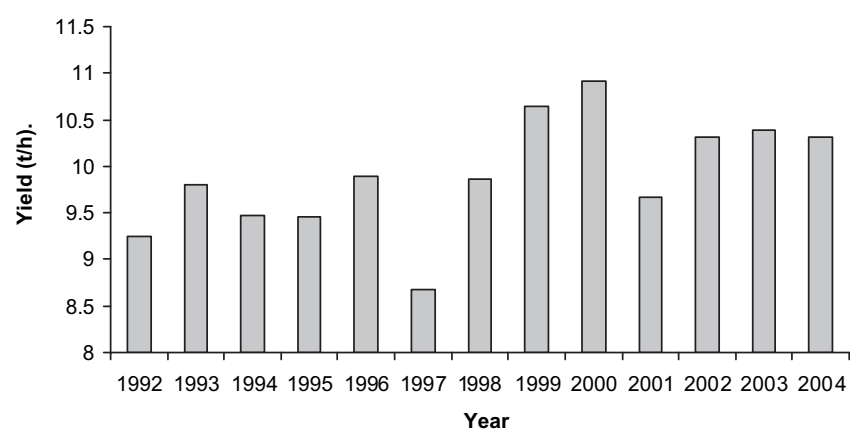

Fig. 3. Mean yield for all cultivars, sites and years. 
Table 2

Summary statistics on AOT40 and yields by cultivar, measured in $\mathrm{t} / \mathrm{ha}$ for the period 1992-2004.

\begin{tabular}{lccc}
\hline & Mean & Minimum & Maximum \\
\hline AOT40 (ppb h) & 3169 & 661 & 8592 \\
Yield for all (t/ha) & 10.02 & 4.23 & 15.65 \\
Consort (t/ha) & 10.08 & 5.22 & 14.16 \\
Hereward (t/ha) & 9.04 & 4.81 & 13.14 \\
Riband (t/ha) & 9.64 & 5.00 & 14.04 \\
Soissons (t/ha) & 8.70 & 5.16 & 12.31 \\
\hline
\end{tabular}

the deleterious effect of sequential cropping with the same species. A very similar result is obtained if sugar beet was the previous crop, as that is also soil-depleting. In contrast, if beans, which increase soil nitrogen levels due to $\mathrm{N}_{2}$ fixation in their root modules, were the preceding crop, the average yield was increased by approximately $8 \%$. By comparison, a marginal (1\%) increase in ozone reduces yield by only $0.054 \%$, which is the slope of the function in natural logarithms.

The basic result is as expected, in that the trial plots all tend to grow all the cultivars, so there is no attempt to select for ozone tolerance in an area with high ozone levels. Thus, the impact of ozone at the trial plot level is over twice as great as farm level estimates. The more difficult problem is to discover how much damage ozone would have done if plant breeders had not possibly inadvertently selected for ozone tolerance over a long period. If this can be established, it would help to explain why the early econometric studies gave much larger elasticities (Garcia et al., 1986; Young, 1993).

Fig. 5 summarizes the results of the fumigation experiment, showing the percentage of yellowed and damaged leaves for each cultivar from both filtered air and $\mathrm{O}_{3}$ treatments. The most striking result is that the last three cultivars show significantly much lower levels of leaf senescence, with or without ozone (injury in the controls represented natural senescence). Indeed, whatever its other attributes, Avalon (introduced in 1983) seems to be particularly robust. While $\mathrm{O}_{3}$ data in the 1970 s are sparse, there were some very high levels, especially in the drought years of 1975 and 1976 (Lea, 1998), which may have played a part in Maris Huntsman replacing Cappelle Desprez as the most widely used cultivar. However, although the differential effect of ozone on leaf senescence is less significant for Maris Huntsman than for Cappelle Desprez, the former seems to be prone to a high level of plant damage from other causes. Still, there is no doubt that Avalon had the lowest levels of leaf senescence all around compared to previous varieties. Overall, the three most recently introduced cultivars show some indication of increased $\mathrm{O}_{3}$ tolerance compared with those developed prior to the 1970s.

\section{Discussion}

In contrast to most previous exercises which utilise extrapolations from experimentally derived dose-response relationships we have made an attempt to relate yields to $\mathrm{O}_{3}$ exposure using yield data from a wide range of cultivars of one major crop growing under field conditions. This has the advantage over the approach of Shankar and Neeliah (2005), who also used farm data, in that yields were obtained from plots where environmental variables were controlled to some extent and agronomic treatments in the form of fertiliser and pesticide application were standardised so as to maximise productivity. This removes the need to model the farm production process with a full range of inputs, such as labour, chemicals and machinery. The GIS study indicates that much of Britain, especially southern England, is regularly subjected to $\mathrm{O}_{3}$ doses in the growing season which exceed, in some years substantially, the critical level for agricultural crops. It can thus be predicted with a high degree of confidence that $\mathrm{O}_{3}$-induced yield reductions will occur in winter wheat, a crop which is classed as sensitive to this pollutant (Pleijel et al., 2007). The most recent major study on wheat and ozone is by Feng et al. (2008), who quantified the impact of the pollutant using a meta-analysis of data published between 1980 and 2007. This showed that elevated $\mathrm{O}_{3}$ concentrations, with a range of 31-200 ppb, decreased wheat grain yield by $29 \%$, with a $95 \%$ CI of $24-34 \%$. Mills et al. (2007) used a literature review to establish the $\mathrm{O}_{3}$ dose-response functions for a wide range of agricultural and horticultural crops. Wheat was ranked among the most sensitive with 5\% yield loss at AOT40 of $3000 \mathrm{ppb}$ h. However, the actual magnitude of yield loss has not been clearly identified in terms of field productivity, but the data in Table 2 suggest losses ranging from c.0.5-15\% for a recent 12 -year period in the UK.

The AOT40 maps seem to correspond well to the actual AOT40 levels, capturing the general trend of declining concentrations from the south-east northwards and similar to the maps developed by the Centre for Ecology and Hydrology (CEH) expert team (Coyle et al., 2002; Reynolds et al., 2003). They also indicate that the central part of the country has lower ozone concentrations. However a certain amount of discrepancy is expected. A few stations were initially removed from the sample in order to compare their predicted values with their measured values. The outcome of the validation indicated that predicted values seem to

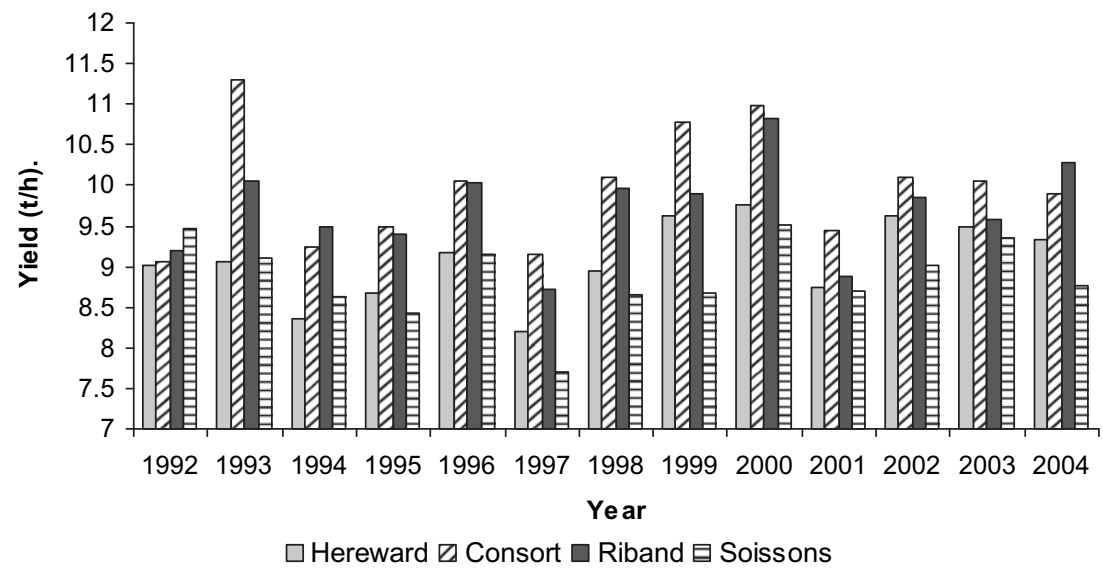

Fig. 4. Annual mean yield for four varieties. 
Table 3

Ordinary least squares (OLS), one and two-way fixed effects and error components.

\begin{tabular}{|c|c|c|c|}
\hline Model & Log-likelihood & SSE & $R^{2}$ \\
\hline Constant term only & 3312 & 271 & 0 \\
\hline $\begin{array}{l}\text { Pooled OLS ( } X \text { variables only - years } \\
\text { and last crop) }\end{array}$ & 4138 & 227 & 0.16 \\
\hline One-way fixed effects (site only) & 6259 & 144 & 0.47 \\
\hline One-way fixed effects and $X$ variables & 7160 & 119 & 0.56 \\
\hline $\begin{array}{l}\text { Two-way FE (site and year) with } \\
X \text { variables - main variables }\end{array}$ & 7407 & 113 & 0.58 \\
\hline $\begin{array}{l}\text { Two-way fixed effects (site and varieties) } \\
\text { and } X \text { variables - years and previous crop }\end{array}$ & 7753 & 105 & 0.61 \\
\hline
\end{tabular}

correspond quite well to the measured values with deviations varying on average between 5 and $10 \%$.

Further support for use of modelling of $\mathrm{O}_{3}$ concentration is provided by Klingberg et al. (2008) who compared measured and modelled data at a single site in southwest Sweden and found good agreement for daytime measurements, but with potential for errors introduced by very local climatic conditions. It was not possible to take the latter into account in the present work.

Shankar and Neeliah (2005) illustrate their result by showing that the yield loss of a farm in the South East with high $\mathrm{O}_{3}$ is $1.6 \%$ relative to the $\mathrm{O}_{3}$ levels on Humberside. Our elasticity of -0.054 would imply a loss of $3.7 \%$, which is not trivial, but much lower than the loss suggested by experimental methods. The higher value for yield loss from our study compared with that based on farm yields may well be explained by selection for $\mathrm{O}_{3}$ tolerance by plant breeders and utilisation by farmers of the more tolerant cultivars for which our fumigation study provides limited support. However, variation in agronomic practices between farm and trial plots, for example in terms of irrigation and thus ozone flux rates, may also contribute to differences in yield loss estimates.

The present study contrasts with two previous studies which have addressed the issue of selection for tolerance Barnes et al. (1990) fumigated 10 cultivars of spring wheat, both Triticum aestivum and Triticum durum, bred and introduced in Greece between 1932 and 1980 , with 90 ppb $\mathrm{O}_{3}$ for 21 days. They found that mean relative growth rate was depressed by the pollutant with a positive relationship between date of introduction and $\mathrm{O}_{3}$ sensitivity i.e. the more modern cultivars were more $\mathrm{O}_{3}$ sensitive. They suggested that breeding programmes may have selected for sensitivity, in direct contrast to the present study and intuitively against expectations, although $\mathrm{O}_{3}$ tolerance may be linked to other characteristics

Table 4

Coefficients for the two-way fixed effects model.

\begin{tabular}{lllcl}
\hline$X$ variables & Elasticity & Standard error & $t$-statistic & $p$-value \\
\hline Ozone & -0.05381 & 0.00891083 & -6.039 & $0^{* * *}$ \\
Cereal previous & -0.0893 & 0.00533674 & -16.733 & $0^{* * *}$ \\
1992 dummy & -0.06024 & 0.01083608 & -5.559 & $0^{* * *}$ \\
1993 dummy & -0.04589 & 0.0090237 & -5.085 & $0^{* * *}$ \\
1994 dummy & -0.09257 & 0.00844621 & -10.96 & $0^{* * *}$ \\
1995 dummy & -0.10649 & 0.00775644 & -13.73 & $0^{* * *}$ \\
1996 dummy & -0.05392 & 0.00765308 & -7.045 & $0^{* * *}$ \\
1997 dummy & -0.18471 & 0.00718217 & -25.718 & $0^{* * *}$ \\
1998 dummy & -0.12235 & 0.00898007 & -13.624 & $0^{* * *}$ \\
2000 dummy & -0.01189 & 0.00710998 & -1.672 & $0.0945^{*}$ \\
2001 dummy & -0.14561 & 0.0065306 & -22.297 & $0^{* * *}$ \\
2002 dummy & -0.10452 & 0.00873306 & -11.968 & $0^{* * *}$ \\
2003 dummy & -0.08426 & 0.00692837 & -12.162 & $0^{* * *}$ \\
2004 dummy & -0.12563 & 0.00881815 & -14.247 & $0^{* * *}$ \\
Constant & 2.828322 & 0.07296626 & 38.762 & $0^{* * *}$ \\
\hline
\end{tabular}

Estimated coefficients, $t$-statistic, standard errors and $p$-values, for ozone and dummies for previous crop being cereal and dummies for years.

${ }^{* * *} p<0.001,{ }^{* *} p<0.05,{ }^{*} p<0.1$, indicate the level of significance $5 \%$.

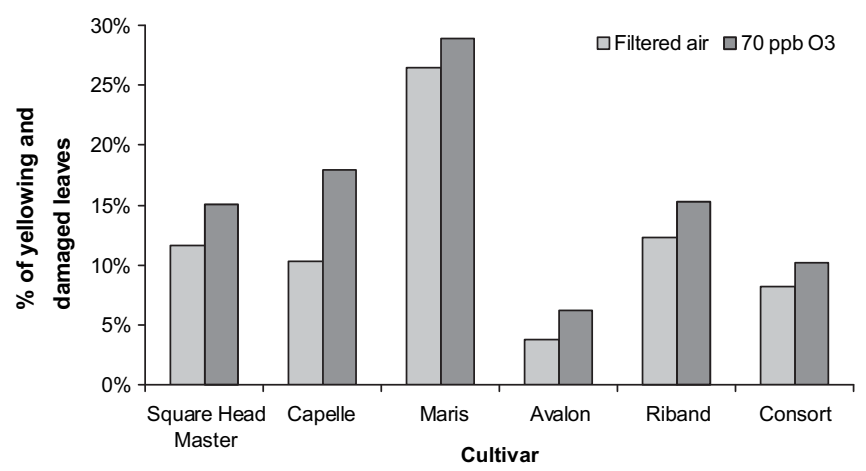

Fig. 5. Percentage of yellowing and damaged leaves to wheat plants grown in filtered air and ozone $(70 \mathrm{ppb})$. The varieties are presented in order of the era that they were used.

selected for in the breeding process. However, it should be noted that in both Barnes et al. (1990) and the present study the fumigation lasted only 3-4 weeks and thus did not demonstrate the impact on grain yields.

The other study, carried out by Pleijel et al. (2006), compared the response of a modern and a 100-year old cultivar of spring T. aestivum to $40 \mathrm{ppb}$ above ambient $\mathrm{O}_{3}$ or filtered air, grown to maturity. Again the modern cultivar showed higher sensitivity to $\mathrm{O}_{3}$ based on a number of parameters, including growth and yield; this was at least partly attributable to higher stomatal conductance in the modern cultivars, a characteristic with potential benefit in terms of increased yield, but with consequences for pollutant uptake.

At present it is difficult to generalise from available evidence concerning selection of $\mathrm{O}_{3}$ tolerance in the plant breeding process. However, it should be noted that in this case winter cultivars were employed while the cultivars studied by Barnes et al. (1990) and Pleijel et al. (2006) were all spring sown. In our work Avalon appears to represent a breakthrough in terms of tolerance to both $\mathrm{O}_{3}$ and other constraints on growth. Although we cannot report the actual yield gain resulting from this cultivar, due to termination of the experiment after 4 weeks, $\mathrm{O}_{3}$ effects on leaf injury and senescence were reduced by approximately $50 \%$ compared with previous cultivars in the time series.

\section{Conclusions}

While this single study suggests lower yield losses than predicted by extrapolation from experimental dose-response experiments, further work is clearly needed in order to determine the real yield losses occurring in the field due to tropospheric $\mathrm{O}_{3}$. We have used one crop species, albeit with a large number of cultivars, from one dataset in a single country. However, we feel that our approach is well worth extending to other crops in both Britain and elsewhere, where suitable yield and pollution datasets are available. This would enable many more comparisons to be made between the experimental and econometric approaches, in order to move towards more realistic estimates of $\mathrm{O}_{3}$ impacts on yield, with considerable potential for air pollution control policy formulation. Ultimately, clarification of this important environmental issue will depend upon the adoption of an interdisciplinary approach and we hope that our research contributes to this debate.

\section{Acknowledgements}

We thank the Home Grown Cereals Authority for permission to use their trial plot yield data for this research and the National 
Institute of Agricultural Botany for provision of historical seed cultivars. The experimental work was supported by a grant from Imperial College London's Faculty of Life Sciences Research Fund.

\section{References}

Ashmore, M.R., 2002. Effects of oxidants at the whole plant and community level. In: Bell, J.N.B., Treshow, M. (Eds.), Air Pollution and Plant Life, second ed. John Wiley and Sons, Chichester, pp. 89-118.

Atkins, D.H.F., Cox, R.A., Eggleton, A.E.J., 1972. Photochemical ozone and sulphuric acid aerosol formation in the atmosphere over southern England. Nature 235, 372-376.

Baltagi, B., 2005. Econometric Analysis of Panel Data, third ed. John Wiley and Sons, Chichester.

Barnes, J.F., Velissariou, D., Davison, A.W., Holeves, C.D., 1990. Comparative ozone sensitivity of old and modern Greek cultivars of spring wheat. New Phytologist $116,707-714$.

Baum, C.F., 2006. An Introduction to Modern Econometrics Using Stata. Stata Press, College Station, US.

Bonham-Carter, G.F., 1994. Geographic Information Systems for Geoscientists Modelling with GIS. Pergamon, Oxford.

Coyle, M., Smith, R.I., Stedman, J.R., Weston, K.J., Fowler, D., 2002. Quantifying the spatial distribution of surface ozone concentration in the UK. Atmospheric Environment 36, 1013-1024.

Diem, J.E., Comrie, A.C., 2002. Predictive mapping of air pollution involving sparse spatial observations. Environmental Pollution 119, 99-117.

Feng, Z., Kobayashi, K., Ainsworth, E., 2008. Impact of elevated ozone concentration on growth, physiology, and yield of wheat (Triticum aestivum L.): a metaanalysis. Global Change Biology 14, 2696-2708.

Fuhrer, J., Skärby, L., Ashmore, M.R., 1997. Critical levels of ozone effects on vegetation in Europe. Environmental Pollution 97, 91-106.

Garcia, P., Dixon, B.L., Mjelde, J.W., Adams, R.M., 1986. Measuring the benefits of environmental change using a duality approach: the case of ozone and Illinois cash grain farms. Journal of Environmental Economics and Management 13, 69-80.

Holland, M., Kinghorn, S., Emberson, L., Cinderby, S., Ashmore, M., Mills, G. Harmens, H., 2006. Development of a Framework for Probabilistic Assessment of the Economic Losses Caused by Ozone Damage to Crops in Europe. Centre for Ecology and Hydrology, Bangor.

Home Grown Cereals Authority (HGCA). Winter Wheat Trial Plots Data. <http:// www.hgca.com/varieties/rl\%2Dplus/> (Date accessed: 10.2.2006).

Home Grown Cereals Authority (HGCA) Recommended List; Cereal Trials Protocol, 2007-2008. < http://www.hgca.com/document.aspx?fn=load\&media_id=4244\& publicationId $=262>$ (Date accessed: 03.08.2008).

Hunova, I., Livorova, H., Ostatnicka, J., 2003. Potential ambient ozone impact on ecosystems in the Czech Republic as indicated by exposure index AOT40. Ecological Indicators 3, 35-47.
Klingberg, J., Danielsson, H., Simpson, D., Pleijel, H., 2008. Comparison of modelled, measured ozone concentrations, meteorology for a site in south-west Sweden: implications for ozone uptake calculations. Environmental Pollution 115 99-111.

Landau, S., Mitchell, R., Barnett, V., Colls, J., Craigon, J., Payne, R., 2000. A parsimonious, multiple regression model of wheat yield response to environment. Agricultural and Forest Meteorology 101, 151-166.

Lea, P.J., 1998. Oxides of nitrogen and ozone: can our plants survive? New Phytologist 139, 25-26.

Loibl, W., Winiwarter, W., Kopsca, A., Zufger, J., Baumann, R., 1994. Estimating the spatial distribution of ozone concentrations in complex terrain. Atmospheric Environment 28, 2557-2566.

Mills, G., Buse, A., Gimeno, B., Bermejo, V., Holland, M., Emberson, L., Pleijel, H., 2007. A synthesis of AOT40-based response functions and critical levels of ozone for agricultural and horticultural crops. Atmospheric Environment 41, 2630-2643.

Ollerenshaw, J.H., Lyons, T., 1999. Impacts of ozone on the growth and yield of fieldgrown winter wheat. Environmental Pollution 106, 67-72.

Pleijel, H., Berglen Eriksen, A., Danielsson, H., Bondesson, N., Selldén, G., 2006. Differential ozone sensitivity in an old and a modern Swedish wheat cultivar-grain yield and quality, leaf chlorophyll and stomatal conductance. Environmental and Experimental Botany 56, 63-71.

Pleijel, H., Danielsson, H., Embersson, L, Ashmore, M.R, Mills, Q, 2007. Ozone risk assessment for agricultural crops in Europe: further development of stomatal flux and flux-response relationships for European wheat and potato. Atmospheric Environment 41, 3022-3040.

PORG, 1997. Ozone in the United Kingdom: Fourth Report of the Photochemical Oxidants Review Group. Department of the Environment, Transport and the Regions, London.

Reynolds, B., Fowler, D., Coyle, M., Leith, I., Evans, C., Nisbet, T., Broadmeadow, M. 2003. Air Pollution Monitoring in the UK. Joint Nature Conservation Committee (JNCC) Air Pollution and Ecosystem Symposium. < http://www.jncc.gov.uk/PDF/ reynolds.pdf> (Date accessed: 11.03.2008).

Shankar, B., Neeliah, H., 2005. Tropospheric ozone and winter wheat production in England and Wales: a note. Journal of Agricultural Economics 56, 145-151.

Sillman, S., 1999. The relation between ozone, $\mathrm{NO}_{\mathrm{x}}$ and hydrocarbons in urban and polluted rural environments. Atmospheric Environment 33, 1821-1845.

UK National Air Quality Information Archive. <www.airquality.co.uk>.

UNECE convention on long range transboundary air pollution (LRTAP), 2004. Manual on Methodologies and Criteria for Modelling and Mapping Critical Loads and Levels and Air Pollution Effects, Risks and Trends. <http://icpmapping.org/cms/ zeigeBereich/11/manual-english.htmlchapter 3> (Date accessed: 11.10.2009).

Young, D.A.S., 1993. Ozone and wheat farming in Alberta: a micro-study of the effects of environmental change. Canadian Journal of Agricultural Economics 41, 27-43. 